\title{
DAS SIGNIFICAÇÕES NA LÍNGUA AO SENTIDO NA LINGUAGEM: PARÂMETROS PARA UMA ANÁLISE DIALÓGICA
}

\author{
Adail Sobral $^{*}$ \\ Universidade Católica de Pelotas \\ Centro de Ciências Sociais e Tecnológicas \\ Pelotas, RS, Brasil \\ Karina Giacomelli ${ }^{*}$ \\ Universidade Federal de Pelotas \\ Centro de Letras e Comunicação \\ Pelotas, RS, Brasil
}

\begin{abstract}
Resumo: A proposta aqui apresentada, que constitui parte de trabalhos em andamento, baseia-se na teoria dialógica da linguagem e envolve um tratamento integrado do plano linguístico-textual mais estrito (a chamada materialidade textual) e do plano enunciativo mais amplo. Neste sentido, o interesse específico da proposta é apresentar parâmetros para um trabalho linguístico-discursivo que parta, ao mesmo tempo, da palavra no sistema da língua (nível da significação) e de enunciados efetivamente produzidos (nível do sentido) para verificar de que maneiras as significações na língua são apropriadas pelos discursos e servem à instauração de sentidos na linguagem. Esta concepção parte da ideia de que as palavras não têm um sentido dado, mas adquirem sentido nos contextos de uso, que envolvem a interação entre interlocutores específicos, em esferas de atividade e mediante gêneros.
\end{abstract}

Palavras-chave: Dialogismo. Teoria e análise. Parâmetros analíticos.

1 INTRODUÇÃO

Este texto pretende apresentar as bases de uma análise dialógica de textos com base na exploração das relações entre os conceitos de significação (que é do plano da língua como sistema) e de sentido, ou tema (que é do plano da linguagem). As significações se manifestam em frases, unidades da língua, e, os sentidos, em enunciados, unidades da linguagem em uso, da atualização efetiva das possibilidades expressivas da língua (cf. BAKHTIN (VOLOSHINOV), 1999; BAKHTIN, 2003; SOBRAL, 2006, 2009; SOBRAL; GIACOMELLI, 2016). Com esse fim, ele traz considerações teóricas, proposições metodológicas e um exemplo prático da metodologia de análise cuja apresentação é seu objetivo.

\footnotetext{
* Doutor em Linguística Aplicada e Estudos da Linguagem pela Pontifícia Universidade Católica de São Paulo. Docente e Coordenador do Programa de Pós-graduação em Letras. E-mail: adail.sobral@gmail.com.

** Doutora em Letras pela Universidade Federal de Santa Maria. Professor Associado da Universidade Federal de Pelotas. E-mail: karina.giacomelli@gmail.com.
} 
Nesta Introdução, fazemos uma breve descrição geral da teoria e análise dialógica, destacando os pontos mais relevantes para os objetivos deste texto, qual seja as significações e o sentido, a fim de dar consistência às partes seguintes do texto.

Partindo de considerações gerais acerca da proposta dialógica de que o sentido não é propriedade das palavras, mas surge nas situações de interação, abordamos as relações entre interlocução e sentido, o que envolve diversas considerações sobre a questão do sujeito para a teoria dialógica, da interconstituição dos sujeitos entre si na sociedade e na história, bem como da questão da valoração e da ideologia, a par da questão do discurso e das relações entre sujeito concreto e imagem discursiva.

Em seguida, apresentamos as principais bases metodológicas de nossa proposta, de forma didática, como postulados, que são explicados no texto. O objetivo dessa seção consiste em mostrar a integração entre teoria e prática sem o recurso a uma rigidez categorial que fizesse buscas nos textos estudados as categorias teóricas que servem de base à análise. A proposta aqui feita é precisamente a de derivar da teoria e de objetos de análise uma metodologia, mostrando assim o dinamismo da teoria dialógica em termos de seu valor heurístico e descritivo, em vez de prescritivo e formal. Por isso, é nessa seção que fazemos uma análise ilustrativa dos parâmetros propostos, a fim de melhor discutir seus desdobramentos na seção seguinte.

Depois mostramos a concepção de análise linguístico-discursiva que decorre dos postulados, cuja pertinência é demonstrada pela análise ilustrativa. Nela, retomamos os vários elementos relevantes dos referidos postulados, bem como aquilo que a análise ilustrativa revela, a fim de chegar a uma síntese de nossa proposição como um todo.

Nas considerações finais, fazemos uma síntese do que desenvolvemos no texto ao apresentar nossos "marcos da análise". Os postulados, como se verá, têm caráter sobremodo geral, sendo mais teórico; os desdobramentos são um pouco menos gerais e, ainda que também teóricos, têm caráter mais propriamente metodológico. Os marcos da análise são ainda mais específicos, e sintéticos, e assumem a forma de itens organizados do geral para o particular.

\section{BREVE DESCRIÇÃO DA TEORIA E ANÁLISE DIALÓGICA}

Considera-se no âmbito da teoria e análise dialógica do discurso que o sentido advém das relações enunciativas entre interlocutores, não de forma independente da língua, mas também não restrito às significações. Estas podem ser mais ou menos cristalizadas, sendo que os locutores não desprezam sua experiência com o sistema da língua, mesmo que precisem necessariamente ir além dela ao enunciar. Os contextos de uso podem fazer que uma palavra de significação negativa no dicionário adquira sentidos positivos. Tudo depende de quem diz o que a quem, em que circunstância, quando e de que maneira, envolvendo a negociação de sentidos na situação de produção de discursos. É, portanto, a relação enunciativa que determina os sentidos possíveis realizados nas interações.

Assim, as significações não são o fator determinante, embora sejam indispensáveis para a instauração de sentidos. Nesse sentido, ainda que se considerem diferentes 
acepções de uma dada palavra, a produção de sentidos mobiliza essas acepções para seus fins específicos, ideologicamente marcados, em vez de restringir-se a significações cristalizadas. Importa para a concepção dialógica a mobilização de significações na língua para criar sentidos na linguagem (Cf. BAKHTIN/VOLOSHINOV, 1999; BAKHTIN, 2003).

Falar, enunciar, é, desse modo, um ato que cria uma ligação entre o sistema linguístico e o sistema concreto de relações sociais, que chegam à nossa consciência por meio dos enunciados, dos discursos. No enunciado, os sentidos só são compreensíveis se levarmos em conta a negociação permanente entre os seres humanos em sociedade por meio de suas atuações, verbais e outras. Entende-se por negociação permanente os esforços desses seres de propor uns aos outros - e por vezes de impor - os sentidos que pretendem, em seu projeto enunciativo, dando, àquilo que dizem, sentidos que podem ser aceitos quase inteiramente ou quase inteiramente rejeitados, passando por todas as variações intermediárias. Os sentidos nascem também da atitude da pessoa a quem se fala e da relação que ela mantém com o locutor, podendo surgir, muitas vezes, sentidos que não são exatamente aqueles que o locutor pretendia propor, nem aqueles que o interlocutor propôs, mas sentidos criados e tornados comuns na e pela própria interação.

Quando o locutor se acha diante do interlocutor, isso acontece a partir da vivência comum na situação, ainda que não se reduza a isso; no caso de textos escritos, quem escreve precisa, por assim dizer, reproduzir a situação na qual escreveu para dar a quem lê pistas que levem a entender os sentidos que propõe. Em todos os casos, ao enunciar, leva-se em conta o que se acha que o outro pode dizer, o que ele de fato já disse, o que já se disse, o que outras pessoas disseram outrora, o que se antecipa que pode vir a ser dito etc. - claro que não exaustivamente. E a pessoa que ouve ou lê entende e avalia o que é dito levando em conta todas essas coisas, mas sempre nos termos da relação específica que tem com quem disse, mediata e imediatamente (BAKHTIN, 2003; BAKHTIN (VOLOSHINOV), 1999).

\section{INTERLOCUÇÃO E SENTIDO}

Se não se aparta a produção de sentidos da imagem discursiva dos interlocutores, também não se podem considerar estes últimos equivalentes a sujeitos empíricos. Os sentidos só vêm a ser na interação, que depende da imagem dos sujeitos, mas estes são, do ponto de vista do discurso, seres de linguagem, o que mostra que apartar esses planos é seccionar componentes, intimamente integrados, de um mesmo todo, correspondentes a distintos momentos (no sentido filosófico) seus. A concepção integrada evita a fragmentação do discurso, e mesmo sua desfiguração.

Por conseguinte, a perspectiva teórica aqui seguida no tocante à natureza da enunciação e do caráter das marcas da enunciação presentes ao enunciado vê estas últimas como fiadoras da convocação do extra-discursivo quando da análise de fenômenos discursivos. Parte-se da ideia de que a enunciação é o espaço por excelência da mobilização, que se quer unitária e coerente, do repetível (seu produto) e do irrepetível (seu processo), ambos presentes no agir enunciativo do sujeito. Essa mobilização gera um dado, um enunciado ou conjunto de enunciados, que é a base dos estudos, quer por sua materialidade específica, quer por sua organicidade a serviço da criação de sentidos. 
A enunciação deixa nos enunciados marcas que são tanto materiais (marcas linguísticas) como da ordem do sentido (marcas enunciativas). As marcas da ordem da língua, da estabilidade, são um dos planos considerados, dado que todo estudo do discurso as leva necessariamente em conta, não se restringindo, porém, sob pena de parcialidade, nem aos tipos relativamente estáveis de enunciados que constituem os gêneros de discurso, nem aos elementos extra-verbais de mobilização da textualidade dos discursos para a criação de sentidos - e que estão inscritos em sua própria estrutura.

O eu que fala, não obstante sua multiplicidade, tem necessariamente a ilusão, por vezes intensa, de ser um sujeito unificado, e essa ilusão é compartilhada pelos interlocutores. Constituído a partir das relações com o outro, tanto em termos abstratos como concretos, a partir da situação de enunciação, presumida ou representada, o eu também constitui esse outro. Precisa, por isso, conceber a si mesmo como identidade unificada, tanto na vida em geral como especificamente no momento da enunciação, dado que uma coletividade não fala senão pela mediação de um sujeito, não sendo este um item descartável ou um fantoche das relações sociais, mas uma concretude definida, e distinta de outras concretudes, base da transfiguração simbólica que cria sujeitos de discurso.

Além disso, o sujeito da enunciação não pode nunca ser apagado, anulado, embora só se faça presente na forma de uma imagem, mesmo quando está diante do outro em carne e osso. Não se trata de uma imagem essencial e inteiramente preexistente, mas de uma imagem construída (e nem por isso menos concreta, dado que chega mesmo a sugerir um corpo) pela situação concreta de enunciação, que ele só pode perceber e construir para si a partir de sua autoimagem e da imagem que o outro faz dele, bem como da imagem que julga que o outro faz dele (o que envolve, naturalmente, a imagem que ele faz do outro).

Ao sujeito cabe assim "saber" - não subjetivamente, em termos psicológicos estritos, mas a partir de sua individualidade singular - o que dizer como dizer e como negociar esse paradoxo de ser mais o portador da palavra de uma imagem de si mesmo do que ele mesmo empiricamente presente. Só lhe resta ser um "personagem de si mesmo", pois só assim pode ele ser um sujeito de discurso e continuar a ser um sujeito concreto. Assim agindo, ele se insere numa rede de interlocução em que ocupa diferentes posições-eu (MEAD, 1934) em diferentes situações enunciativas. As marcas do concreto inscritas por esse processo de objetivação do sujeito empírico no corpo do discurso autorizam a convocação do extradiscursivo, que é intradiscursivizado: a constituição do sujeito discursivo, intersubjetiva que é, faz-se assim intrassubjetiva; extradiscursiva que começa, torna-se assim intradiscursiva (SOBRAL, 2006, passim).

Nessa descrição da condição social do sujeito discursivo, há elementos para que se superem, de um lado, as limitações de uma concepção do sujeito como ser isolado, em seu agir, dos outros sujeitos e da sociedade, sujeito de um sistema linguístico autônomo, com regras puramente formais de construção de segmentos linguísticos (sujeito "criativo" de um sistema alheio ao todo social e, portanto, "idealista" e abstrato), e, do outro, as deficiências da concepção de um sujeito ausente, substituído pelas determinações sociais ou pelo código, sujeito imerso num mar de significações que lhe são despoticamente impostas por um outro indefinido. 
O sujeito tem, portanto, o estatuto de agente mediador entre os sentidos socialmente possíveis e os discursos efetivamente produzidos em situações concretas, projetadas em sua superfície (SOBRAL, 1999). Cabe ao sujeito mediar um processo que, enquanto lhe define a identidade em meio à sua interação com outros agentes, dele depende para sua própria constituição; ou seja, sujeito e discurso pressupõem-se mutuamente. Nessa perspectiva, se o sujeito deixa de ser o "centro" do processo de produção do sentido, em contrapartida ele não é privado da possibilidade de ação individual, que, na verdade, é vital para a sua interação discursiva (cf. BAKHTIN, 2010).

Faz-se necessário, desse modo, levar sempre em conta a relação entre a linguagem (e os processos linguísticos) e os diferentes elementos da estrutura social, entre os quais tem grande relevância a ideologia. Sabe-se que o ideológico só se manifesta para sujeitos e por meio de sujeitos, e, o que é mais importante, entre sujeitos - ou seja, a individualidade é condição da interindividualidade que a constitui. O caráter sóciohistórico-ideológico da consciência individual não a torna menos individual nem apaga os componentes pessoais da personalidade, embora nem por isso as leis da psicologia individual sejam o determinante do processo social de produção/transformação de sentidos. A própria percepção da realidade se dá em termos de uma construção simbólica, ancorando-se na linguagem, sendo, portanto, já ideológica, dada a íntima ligação linguagem-ideologia, sem que a linguagem se especialize em alguma esfera ideológica.

O sujeito precisa necessariamente reconhecer-se a si mesmo, e ele só o faz a partir do momento em que reconhece o fato de estar sempre em interação com outros sujeitos, na presença (real ou presumida) do outro. De um lado, a identidade individual tem como condição de possibilidade o processo de identificação social e, de outro, essa identidade é condição vital para o existir, simbólico, imaginário, semiótico e real, do próprio social: os sujeitos constituem a sociedade e a sociedade constitui os sujeitos.

Quanto a isso, chamamos a atenção para uma interessante expressão usada por Bakhtin (Voloshinov) (1999) ao falar da relação entre o discurso na vida e o discurso na poesia (ou na arte): "socializar os sentimentos". Aqui, unem-se o individual e o social, indicando que, para ser entendido pelo outro, o sujeito que sente algo e deseja exprimi-lo tem de fazê-lo de uma maneira que leve em conta esse outro. Trata-se de algo tão presente ao sujeito que este, mesmo no solilóquio, "fala" de uma maneira que se assemelha a um diálogo com outra pessoa. Por outro lado, exteriormente o sujeito também é dividido, também é "mais de um" - no mínimo aquele que ele julga ser e aquele que os outros julgam que ele é: ainda que se veja como uma "mesma" individualidade, o sujeito vê- se inescapavelmente no espelho do outro.

O sujeito vê o outro como um ser completo, ser que veio a existir num dado momento que nunca mais se repete, ser que não tem igual, e, assim, mostra ao outro uma imagem do que esse outro "é" enquanto ser íntegro. Mas o sujeito depende do outro, de seu reconhecimento, para ser visto como íntegro, para ser reconhecido, constituído. Ele só tem uma ideia mais clara de si mesmo no contato com o outro, cujas reações lhe mostram coisas sobre si mesmo a que ele não tem acesso (BAKHTIN, 2003).

Esses elementos comprovam que a interação é o lugar em que nasce o sentido: nem o sujeito nem a linguagem constituem a essência da criação do sentido, assim como nem a psicologia individual nem um código social abstrato são o centro do sentido. É no ato de fala que nasce o sujeito e o sistema de signos, a individualidade e a coletividade, ato que só existe para o outro e a partir do outro. Do mesmo modo, se o material que se faz 
presente no uso é o próprio sistema linguístico, com suas significações, este depende do uso para se realizar, para criar sentido. Em resumo, a linguagem é a união entre as possibilidades do conjunto de signos, também mutável, porém mais estabilizado, e as realidades do sistema do uso. Podemos estudar só um dos conjuntos, mas teremos de reconhecer que, agindo assim, estaremos abstraindo, afastando-nos da realidade para nossos próprios fins - o que é legítimo, desde que não se pretenda ser isso um estudo da totalidade do fenômeno enfocado. No tocante à linguagem, portanto, forma, conteúdo, material etc. estão ligados de maneira inseparável na realidade; posso ignorar um ou o outro componente, mas não dizer que aquilo que estudo seja a realidade da linguagem.

O interlocutor é entendido por Bakhtin (2003) como dotado de "responsividade ativa": a sua resposta concreta (realizada e presumida) permite que se materialize a compreensão daquilo que lhe é proposto pelo locutor, e este o propõe em termos de uma dada entoação avaliativa que leva em conta essa resposta. Vale destacar que o retrospectivo e o prospectivo têm como ponto de referência o realizado, o texto efetivamente enunciado, que, insiste Bakhtin, é uma unidade, pois, constituído por outros textos, resulta de um ato que mobiliza esses textos constitutivos, que, sem ele, não teriam sobre que incidir, ao tempo em que remete direta ou indiretamente a textos futuros (ou busca antecipar possíveis objeções etc.), criando assim um todo integrado que não é mera soma de seus elementos constituintes.

Toda e qualquer enunciação, toda e qualquer interação, é parte de uma rede de interlocução em constante fazer-se, abarcando os vários momentos sociais e históricos constitutivos da interação/enunciação e que acaba por afetar as próprias formas fixadas da língua de que parte para instaurar seus sentidos. Na língua, é essencial a oposição entre estabilidade e irrepetibilidade, entre forças centrípetas (que tendem ao centro) e forças centrífugas (que se afastam do centro). No processo contínuo de produção de sentidos, cada diálogo recria sentidos criados por outros diálogos, assim como antecipa diálogos ainda inexistentes, inserindo-os em redes de interlocução mediantes recursos expressivos que a ressignificação instaura. Além disso, à luz desses elementos, o horizonte social que Bakhtin leva em conta de modo algum se esgota no interdiscurso ou no contexto imediato, material mesmo, da interação.

Ao dar primazia ao tema com relação aos significados cristalizados, tanto na constituição como no próprio vir a ser dos sentidos, Bakhtin demonstra que o sentido depende por inteiro do contexto, e que esse contexto de modo algum se esgota na situação imediata. Isso não exclui de modo algum o sistema linguístico enquanto tal, nem os processos cognitivos envolvidos, mas busca ir além deles, integrando-os.

Bakthin/Voloshinov (1999) trata da questão dos vínculos entre ideologia e signo verbal, afirmando que um produto ideológico não só constitui uma parte da realidade natural ou social como reflete e refrata uma realidade que lhe é exterior - nessa perspectiva, um signo sempre se refere a uma realidade da qual faz parte. Os signos estão sujeitos aos critérios de avaliação ideológica, coincidindo o seu domínio com o da ideologia e, por conseguinte, todo produto ideológico tem valor semiótico. Assim, além de refletir e refratar a realidade, tem uma realidade concreta passível de estudo científico. Temos aqui a base de uma produtiva concepção de ideologia fundada no dinamismo do vir a ser das avaliações ideológicas que marcam toda palavra, texto, discurso (SOBRAL, 1999). 
Dado que a compreensão e a consciência só se produzem com base num material semiótico e dado que esse material se institui como realidade concreta, a própria consciência só se constitui na "concretude material dos signos"(VOLOSHINOV, 1976, p. 22). Ou seja, a consciência individual só se constitui no processo de interação social e a partir da materialidade semiótica, que é também ideológica. Na interação entre o individual e o social, a psique anula a si mesma, ou é eliminada, no processo de converterse à ideologia, e a ideologia anula a si mesma no processo de converter-se à psique. Destacamos que o trecho de Voloshinov acima referido indica a interconstituição ativa entre consciência individual e ideologia, que se impregnam mutuamente. Anular ou eliminar é apenas um momento dessa articulação, havendo na verdade uma dialética de interconstituição. Nesses termos, a plenitude ideológica ocorre apenas, mesmo que provisoriamente (uma vez que não há sentidos ideológicos fixados de uma vez por todas), quando se realiza em signo, e a realização em signo só ocorre por meio da plenitude ideológica, numa dialógica tensiva em permanente fazer-se. Como precisa realizar-se no signo ideológico, o sentido depende de sua inscrição na consciência (no mundo interior do sujeito). O sentido requer assim tanto signos como ação da consciência. Assim, o sentido se articula em dois planos: no da significação para a qual aponta e no da direção que indica. Significação remete à língua e à interdiscursividade; direção, ao intercâmbio verbal e ao confronto de vozes, ao lócus da geração do sentido.

Social e pessoal são para o Círculo de Bakhtin elementos imbricados nos próprios discursos, e só aí nos são acessíveis. A concretude da situação do sujeito é levada em conta em sua transfiguração discursiva, em sua construção; logo, não é possível uma separação entre o contexto da interação e a interação propriamente dita, entre o texto e o contexto, entre a realidade discursiva e a realidade propriamente dita, o que uma análise bakhtiniana não admite. A ênfase no sujeito se associa a sua inserção social e histórica. O sujeito está necessariamente vinculado com a sociedade ao tempo em que a constitui: assim como o sujeito é um ser em fazer-se, que busca social e historicamente no outro a sua completude. A sociedade é que se articula para além dos propósitos individuais dos sujeitos, para além da soma desses propósitos, sendo antes marcada pela articulação entre eles no todo social, atravessado sempre pela história, tanto retrospectiva como prospectivamente.

Há uma ênfase num sujeito ímpar que não é definido apenas em termos subjetivos estritos, mas que é objetivado. Isso vem de uma teorização que, como todas, generaliza, mas que, ao contrário de tantas outras, não objetiviza. Ela reconhece que entre o possível e o realizável há um agente que faz escolhas, que avalia, que se compromete. Isso permite afirmar que as teorias do Círculo revelam que só um tratamento abrangente, transdisciplinar, dos fenômenos é capaz de fazer justiça à complexidade do ser, do agir e do significar dos seres humanos.

Cremos ser possível afirmar que as teses do Círculo, seu modus operandi e sua prática analítica dos fenômenos humanos funda-se no reconhecimento da provisoriedade da condição humana, provisoriedade do sentido, cuja base é uma permanente tensão dialógica em que estabilidade e variação se confrontam, em que eu e outro, pessoal e social, geral e particular, fixidez das formas e ressignificação, se constituem e configuram mutuamente, em que a irrepetibilidade irredutível do sensível - base do Ser - e a 
repetibilidade necessária do sensível se interdefinem. A teoria bakhtiniana do discurso, do sentido, ao trabalhar com oposições sustentadas, consegue, assim, teorizar sobre aquilo que não se repete sem se perder na especificidade do concreto e, ao mesmo tempo, sem engessar os atos concretos, uniocorrentes, num teoreticismo estéril tão buscado ainda hoje em nome da suposta necessidade de estabilidade.

O mundo tal como o entendem as obras do chamado Círculo de Bakhtin é um mundo de sentido em constante vir-a-ser, de estabilidade e instabilidade relativas, em que há regularidades suficientes para que se identifiquem atividades-tipo, mas no qual há margem para o reconhecimento de que nada se repete literalmente: a simples escolha daquilo que se repete é já uma transfiguração do repetido (BAKHTIN, 2010). Nada no mundo bakhtiniano se realiza por completo - o que é fonte de sofrimento para o ser humano -, mas nem por isso deixa de contar com suficiente concretude para alimentar a eterna busca do acabamento como ideal inalcançável, mas nem por isso menos mobilizador, que une o agir necessário do sujeito ao necessário agir social em que este pode ser sujeito (cf. SOBRAL, 2005, 2006, 2009).

\section{POSTULADOS PARA UMA ANÁLISE DO SENTIDO NA LINGUAGEM}

O horizonte de estudos aberto por essa concepção dinâmica da linguagem que acabamos de esboçar ultrapassa o estudo propriamente linguístico, tal como tradicionalmente entendido, notadamente quando se consideram as propostas de Bakhtin e Voloshinov, e enseja, no limite, tentativas de uma verdadeira interdisciplinaridade no campo das ciências do homem (cf. BARROS, 1997). Nos termos dessa perspectiva, a significação é definida como um processo social contínuo de instauração de eventos significativos. A produção de sentidos deve assim ser analisada levando-se em conta necessariamente o contexto histórico-social interativo em que são produzidos os discursos, por ser este contexto constitutivo do sentido, tal como se manifesta nas superfícies discursivas.

A linguagem é caracterizada como um sistema semiótico em constante fluxo que é constituído social e historicamente; ela transcende a função referencial-informativa, servindo primordialmente à manifestação de intenções, regras, convenções e outros elementos pertinentes ao caráter social e histórico do intercâmbio social, em que estão presentes os processos ideológicos.

Opondo-se ao que chama de "fala monologal isolada" enquanto objeto do estudo linguístico, Bakhtin/Voloshinov (1999) destaca o fato de o falante não receber uma língua pronta, mas, em vez disso, ser introduzido na corrente do intercâmbio verbal. Todo locutor dirige-se a um outro sujeito socialmente organizado e, na ausência de um interlocutor concreto, pressupõe um na pessoa de um representante típico do grupo social a que pertence esse outro sujeito (questão que, como veremos, recebe de Benveniste, sob outra perspectiva, formulação semelhante). Em suma, para Bakhtin/Voloshinov a realidade da linguagem é o fato social da interação verbal e não um sistema abstrato de formas idênticas, nem a fala monologal isolada ou o ato psicofisiológico de realização da fala. 
A partir dessas teorizações, o discurso pode ser caracterizado preliminarmente como o espaço em que a prática linguística constitui seus atores e determina seus sujeitos. O falante é caracterizado como um mediador entre as significações socialmente concretizáveis e permitidas e os discursos efetivamente produzidos de que esse falante pode vir a ser sujeito. Ao destacar a ação linguística e os agentes linguísticos, essa abordagem remete aos próprios fundamentos da noção de sujeito e de realidade.

Impõe-se a partir disso examinar as práticas linguísticas em suas relações com as outras práticas sociais, bem como determinar a influência que têm no discurso os contextos e situações históricas e sociais em que se manifesta o intercâmbio social - passo importante para o dimensionamento do ser e do agir sociais da linguagem.

Trata-se de um exame do sentido linguístico tal como se manifesta na constituição de uma unidade, o discurso, formalmente mais complexa do que a frase - mas que pode manifestar-se por uma única frase - e determinada funcional e significativamente pela configuração concreta da situação de interação no âmbito da qual vem a ser, assim como pelas diferentes estratégias discursivas que estruturam a direção do discurso.

Num primeiro momento, apresentamos os três postulados que descrevem os aspectos globais da proposta ${ }^{1}$ que aqui defendemos e que será exemplificada a partir de um texto de Cony $(2007)^{2}$.

(a) Por meio do texto, tem-se acesso imediato, mas não transparente, ao discurso. O texto, embora traga marcas da enunciação, não pode remeter diretamente à cena enunciativa de sua produção. Não obstante, como convergem para ele as formas da língua e de textualização (marcas linguísticas) e as marcas do cenário de sua produção (marcas enunciativas), pode-se reconstituir sua arquitetônica levando em conta seu contexto.

Para isso, cabe obter informações acerca de seu locutor, seus interlocutores presumidos, a situação de sua produção, a esfera de atividades em que surgiu e circula, porque o texto, embora aponte para esses elementos, não os apresenta diretamente. Sem esses elementos, a análise não avança ou corre o risco de se tornar mera especulação. Sem o texto ou apenas com o texto, o analista não tem como chegar ao processo enunciativo. Por exemplo, Carlos Heitor Cony fala de "gestores e gestantes". Em nenhum momento ele menciona nomes. Na época, isso não era necessário, porque havia mais um escândalo envolvendo a gravidez de uma amante (gestante) do então presidente do Senado (gestor). Hoje, sem essas informações, o sentido crítico e irônico do texto não poderia ser apreendido e talvez ele fosse lido como uma crônica bem humorada sobre gestores e gestantes.

(b) O discurso é criado para produzir efeitos de sentido. Estes englobam todos os aspectos do cenário de sua produção, que é sempre irrepetível. Mesmo que se repita uma mesma frase, o enunciado de que ela é parte não se repete. Não se confunde o texto da frase com o sentido do enunciado que mobiliza essa frase. Por isso, cada discurso específico autoriza um dado conjunto de elementos analíticos a ser mobilizados em seu exame.

\footnotetext{
${ }^{1}$ A base dessa proposta tem como fontes mais específicas um trabalho de Sobral (2006) e outro de Sobral e Giacomelli (2016a), tendo sido objeto de uma comunicação conjunta no VIII SENALE (SOBRAL; GIACOMELLI, 2016b).

${ }^{2}$ Trata-se do texto A gestante de Carlos Heitor Cony, publicado na Folha de S. Paulo em 5 de junho de 2007.
} 
Não há categorias aplicáveis diretamente à análise de todo texto, mas há parâmetros gerais (os locutores envolvidos, o tempo e o lugar, a interação) a serem seguidos. A especificidade de cada texto indica que os elementos melhor servem à sua análise (ressignificação, valoração, signo ideológico), são os que vêm de sua base: as relações enunciativas que ele cria. Os principais elementos desse cenário são precisamente o tempo, o lugar e as relações enunciativas entre os sujeitos envolvidos. Nosso exemplo anterior também ilustra este postulado: preciso saber quem é Cony, quando escreveu, a quem se dirigia etc. para entender sua crônica crítica.

(c) Só no discurso, que remete ao contexto cambiante de sua produção, se pode verificar a gênese e o vir a ser do sentido. Assim, o discurso é um objeto semiótico em fazer-se tanto para o olhar do interlocutor como para o do analista. A estabilidade de sua materialidade, de seu existir concreto, garante sua inteligibilidade em geral no plano da significação, mas só seu caráter situado cria sentido.

O entendimento do todo do discurso que mobilizou um dado texto é vital para uma análise. As situações em que se produzem discursos não são imutáveis, mas, pelo contrário, dinâmicas e por isso não há uma correlação entre situação de produção e texto produzido. $\mathrm{O}$ que se pode verificar é a correlação entre um dado discurso e a situação em que foi produzido (como vimos), claro que partindo do texto, mas sempre além dele.

Afirmar que o discurso é "um objeto semiótico em fazer-se" não significa que o analista acompanhe o processo de criação do discurso e sim que ele, ao abordá-lo, está em situação parecida com a do interlocutor: diante do texto desse discurso, ele não pode saber antecipadamente que sentido e que direção o discurso vai tomar (mesmo que tenha algumas pistas).

O texto de Cony começa falando de algo geral, corriqueiro:

“Gestantes, idosos e deficientes físicos têm prioridade nas filas dos bancos.”.

Ele vai progredindo até chegar a seu foco, explicitado no enunciado que encerra o texto: "o gestor sempre arranja um modo de assumir a responsabilidade, por si ou por terceiros". Para isso, vai conduzindo pouco a pouco o leitor a se concentrar na gestante, por meio de quatro parágrafos que vão do geral (esses grupos - primeiro parágrafo) ao específico (a gestante - segundo, terceiro e quarto parágrafos). No quinto parágrafo, no entanto, o foco muda.

Dessa forma, um momento vital de sua arquitetônica é a marca linguística, mobilizada como marca enunciativa que destacamos no enunciado a seguir:

\footnotetext{
"Responsável pela condição da gestante, o gerador (ou gestor) é mais ou menos como o sujeito oculto de uma frase gramatical".
}

Gestor remete tanto a gerador de gestação como a dirigente, o que o gestor em questão era no Senado à época. Assim, se produz uma similaridade entre aquele que gera, que produz, o criador (em relação à genitor, progenitor) e aquele que gerencia ou administra. São palavras de significações diferentes, mas que, colocadas em alternância, 
adquirem um significado equivalente no enunciado. Esse gerador ou gestor é o "responsável pela condição da gestante", informação que seria óbvia se fizesse referência apenas à condição de genitor. Por isso, é possível pensar nessa "responsabilidade" também de duas formas: nessa, já citada em que s significação se torna estável, e em outra com relação ao fato de o gestor precisar gerenciar ou administrar a gestação, sentido que somente é apreendido quando se entende o propósito enunciativo do texto.

Nesse sentido, é interessante observar que esse responsável pela gestação é comparado ao "sujeito oculto" gramatical, que, como se sabe, é o tipo de sujeito sintático que não está expresso, mas que é facilmente reconhecido - na regra, pela terminação verbal; aqui, no texto, pelo conhecimento que se tenha do assunto em questão. Isto é, não se conhecendo a totalidade do enunciado, pode-se pensar que esse sujeito não é expresso porque a gestante não sabe quem é ele, como sugerido em "Há casos". No entanto, essa situação é colocada como um problema para a gestante e não para o gestor, não sendo, nesse caso, necessário ser tratado no texto,

Nessa mesma direção, outro ponto de destaque é:

"Geralmente o gestor acumula as funções de marido da gestante".

Isso remete diretamente ao gestor em questão, que, sabia-se, não acumulava as duas funções, ao contrário do que geralmente ocorre. "Geralmente" indica precisamente que esse não é o caso, mas, ainda assim, o gestor tem de "amparar" a gestante, podendo gerenciar essa questão por si mesmo, assumindo pessoalmente a "responsabilidade" ou delegando-a a "terceiros" - o erário.

Esses momentos vão construindo o sentido do discurso, que não é um comentário sobre gestantes em geral, mas sobre a crítica a um caso específico, então recente. O que esse texto pede em termos de elementos analíticos? Em linhas gerais, que se entenda que esse autor tem uma perspectiva crítica e o interlocutor a quem ele se dirige, pessoas sabedoras do caso do gestor e da gestante. Sem esse saber, o leitor não pode entender devidamente o texto. Ele poderá até mesmo considerar o texto sem sentido, uma "baboseira" sobre idosos, deficientes e, principalmente, gestantes. Com gracinhas como o "teste do sapo" e referências literárias imotivadas (Brás Cubas).

Do mesmo modo, é preciso mobilizar o conceito de ressignificação para entender o jogo de "gerador (gestor)" relativo à gestação/gestante e referente a gerir uma casa do Parlamento, para entender o referente. $\mathrm{O}$ analista, tal como o leitor, precisa mobilizar igualmente conhecimentos do mundo. Tem de lançar mão de elementos de toda a cena enunciativa para entender o texto. Outro conceito necessário é o de valoração e o de resposta ativa, pois o texto traz marcas que indicam um posicionamento, uma opinião, crítica do comportamento do gestor, que somente podem ser entendidas a partir das pistas que vão se apresentando.

Para sabermos disso, devemos atentar para os momentos do texto em que essa valoração vai sendo mais claramente construída, presumindo uma resposta ativa de quem conhece a situação comentada. Por exemplo: "geralmente", "sujeito oculto", "não sabe quem é o gestor", “A gestante tem de ser amparada pelo gestor", "por si ou por terceiros”. 
O texto, via discurso, requer que se levem em conta esses elementos para que o leitor entenda que, embora o tópico sejam gestantes e gestores em termos de gestação, o tema é uma crítica ao então presidente do Senado.

$\mathrm{O}$ discurso por assim dizer escolhe seu interlocutor, e o analista precisa de certo modo colocar-se no lugar deste, não em termos de recepção, mas de reconstituição de sua construção arquitetônica - que é de onde vem o sentido. Isso prova o postulado de que a inteligibilidade em geral no plano da significação está no texto, mas que o sentido vem de seu caráter situado, do fato de ele ter sido escrito num dado momento e lugar, por um dado locutor, o qual se dirigia a um dado interlocutor.

\begin{abstract}
A gestante
CARLOS HEITOR CONY

RIO DE JANEIRO - Gestantes, idosos e deficientes físicos têm prioridade nas filas dos bancos. Nem todos os idosos precisam provar o ano de nascimento com a carteira de identidade. Está na cara que são idosos mesmo. Os deficientes também escapam da prova infelizmente são óbvios.

Com as gestantes a coisa é mais complicada. É preciso esperar alguns meses para que a gravidez fique explícita, inquestionável. Uma gestante de dois meses, querendo invocar o privilégio de não apodrecer na fila, pode mostrar o resultado do laboratório que prova a gestação e aí será merecedora do privilégio.

Ignoro se ainda existe o teste do sapo. A suspeita de uma gravidez era testada num sapo. Não sei se o sapo morria ou apresentava qualquer sinal de anormalidade, mas era tiro e queda para comprovar se a gestante era gestante mesmo.

O respeito às gestantes é um dos pontos simpáticos da civilização humana. Nos ônibus, elas merecem que alguém se levante e ceda o lugar. Trata-se de um cavalheiro. Toda a glória e louvor à gestante.

Responsável pela condição da gestante, o gerador (ou gestor) é mais ou menos como o sujeito oculto de uma frase gramatical. Há casos em que a gestante não sabe quem é o gestor, mas isso é problema dela, mais dela do que do gestor. São exceções à regra. Geralmente o gestor acumula as funções de marido da gestante e se habilita às sobras que devemos àquelas que vão gerar mais um herdeiro do "legado da nossa miséria" - segundo Brás Cubas.

A gestante tem de ser amparada pelo gestor. Em tempos de independência da mulher, ela pode assumir o ônus da gestação, mas, na maioria dos casos, o gestor sempre arranja um modo de assumir a responsabilidade, por si ou por terceiros.

(Fonte: http://feeds.folha.uol.com.br/fsp/opiniao/fz0506200705.htm)
\end{abstract}

\title{
5 DESDOBRAMENTOS DOS POSTULADOS DE ANÁLISE
}

A partir desses postulados, chegamos aos desdobramentos:

(a) $\mathrm{O}$ discurso se funda enquanto espaço de produção de sentidos na relação entre as instâncias de que vem e aquelas a que se dirige. Assim, seu sentido não vem só do linguístico/textual nem só do contextual, nem pode ser tido como apenas subjetivo ou apenas objetivo. O sentido é uma função da intencionalidade conferida aos sujeitos, do qual eles se apropriam, no âmbito das práticas da cultura, da história, etc., ou seja, não advém de algum sujeito individual autônomo que una, de várias maneiras, as instâncias constitutivas. Com isso, não se retira o caráter autoral do agir discursivo do sujeito, mas põe-se em destaque o fato de que seu agir é constitutivamente relacional. 
(b) O objeto a ser estudado é a forma do conteúdo do discurso, o que quer dizer que se vamos estudar num poema o nível fônico devemos fazê-lo do ponto de vista da contribuição que isso pode dar e dá ao sentido do discurso. Logo, não se descrevem os sentidos do discurso em termos de seu conteúdo puro e simples, mas considerando igualmente a forma como nele se dá a instauração de sentido e o material de que ele se serve: o dizer envolve por sua própria natureza o modo de dizer.

(c) Desse modo, a referencialidade situa-se no discurso, sendo instaurada a partir da categorização do mundo dado nos termos das especificidades da interação locutor/interlocutor. Portanto, as expressões linguísticas não são idênticas a coisas do mundo real, mas dispositivos de remissão a entidades de que falam os interlocutores do ponto de vista de sua interação. A referencialidade é uma função advinda da intencionalidade fundadora do discurso, que constitui, em última análise, o próprio elemento desencadeador de sua existência.

Teríamos, nessa relação instauradora, o "grande destinador", o sobredestinatário (ou o supradestinatário), o "grande fiador do discurso", condição primeira de sua possibilidade porque as relações interlocutivas (SOBRAL, 2006, 2009) precedem, mesmo que levem necessariamente em conta, a escolha de um sobredestinatário, de uma instância que garanta a veridicidade do dito perante o locutor e os interlocutores. Logo, o discurso vem essencialmente a ser mediante o dispositivo de instauração dessa intencionalidade, que depende da instauração da relação locutor-interlocutor, a qual depende da instância validadora.

\section{CONSIDERAÇõES FINAIS: MARCOS DA ANÁLISE}

Por fim, chegamos aos marcos da análise, que são uma síntese da proposta.

(a) Respeitar a unidade do discurso: tudo se entende nele com base na conjugação específica que ele faz de dois constitutivos - o de sua estrutura linguístico-textual e o de sua articulação ao contexto. Isso implica examinar a relação de cada componente do discurso com todos os outros em termos de sua dominante enunciativa, naturalmente na medida do humanamente possível. Porque, por sua própria natureza, a produção de sentidos é inesgotável. Há sempre análises possíveis e não a análise definitiva ou completamente exaustiva.

(b) Não perder de vista que a relação entre o locutor e o interlocutor se acha instaurada no discurso e por meio dele é constitutiva de seu sentido; fora dessa relação, não há sentido discursivo.

(c) Distinguir claramente, e de maneira humanamente exaustiva, a linguagem da descrição e a linguagem do objeto, porque, se é o objeto que deve determinar a descrição, esta não deve buscar enquadrá-lo, mas explicá-lo. Toda descrição implica um dado recorte do fenômeno na criação do objeto, que tem de estar claro, a fim de evitar que o analista, por assim dizer, "se leia" no texto em vez de ler o texto.

(d) Examinar o discurso, partindo da superfície material em que ele se configura, para chegar às condições, profundas, tanto da possibilidade do vir a ser do sentido como do vir a ser específico do discurso dado. Isso vai permitir a passagem à próxima etapa, e 
envolve verificar as relações essenciais (internas e externas) a partir das quais ocorre a instauração da relação locutor-interlocutor, que é a base da constituição do sentido.

Isso significa examinar as imagens do locutor e do interlocutor tal como se mostram no discurso a fim de determinar de que maneira o discurso objeto de análise instaura sua intencionalidade e que intencionalidade é essa. Para fazê-lo, examinam-se:

(i) os mecanismos e estratégias discursivos dominantes no discurso dado;

(ii) a sequência na qual se distribuem esses mecanismos no discurso; e

(iii) as inter-relações entre esses mecanismos.

(e) Reconstruir, com base em tudo isso, o percurso contrário, o que vai das condições de possibilidade do sentido aos mecanismos de discursivização. Em outras palavras, tendo descrito na etapa anterior a estrutura manifesta da superfície do discurso, do ponto de vista das relações de interlocução, descrever o percurso que levou a essa materialidade discursiva a partir da intencionalidade desencadeadora do vir a ser da unidade de produção de sentido estudada, voltando assim à superfície. Isso completa o círculo, revelando que a análise considera o tempo inteiro a superfície e a base, o particular e o geral, as especificidades de funcionamento de discursos dados e a similitude das formas de conteúdo dos discursos em geral, com ênfase na inscrição destes nos gêneros e na sua constituição genérica.

Para encerrar, algo que, para a teoria dialógica, é apenas dar um acabamento aos enunciados proferidos, pensemos no que diz Brait (1997) sobre o livro de Voloshinov acerca da filosofia da linguagem, algo que poderia igualmente ser dito de outras obras no âmbito da concepção dialógica. Assim, permanecemos na corrente dialógica, que une no presente o passado aparentemente conhecido e o futuro aparentemente previsível em alguns de seus aspectos. Segundo a autora, a obra de Voloshinov constitui

\footnotetext{
um momento de formalização da possibilidade de estudar o discurso, isto é, não enquanto fala individual, mas enquanto instância significativa, entrelaçamento de discursos que, veiculados socialmente, realizam-se nas e pelas interações entre sujeitos. Sob essa perspectiva, a natureza do fenômeno linguístico passa a ser enfrentada em sua dimensão histórica, a partir de questões específicas de interação, da compreensão e da significação, trabalhadas discursivamente. (BRAIT, 1997, p. 99).
}

A nosso ver, isso significa que o analista, nos termos da proposta apresentada, não pode perder de vista os mecanismos de constituição dos interlocutores e de sua valoração ao instaurar sentidos. Ele deve levar em consideração tanto as estruturas "internas" (por assim dizer), mediante as quais se articula o discurso, como o contexto da enunciação, em suas várias modulações, com ênfase na ação verbal, pretendendo com isso preservar a unidade do discurso. Importa aqui destacar que a realidade a que remete o discurso é já a realidade do discurso: a própria enunciação é já instauração daquilo mesmo que a torna possível. 
BAKHTIN, M. (VOLOSHINOV). Marxismo e filosofia da linguagem. São Paulo: Hucitec, 1999.

BAKHTIN, M. Estética da criação verbal. 4. ed. São Paulo: Martins Fontes, 2003.

Por uma filosofia do ato responsável. São Carlos: Pedro \& João, 2010.

Problemas da Poética de Dostoiévski. 3. ed. São Paulo: Forense, 2002.

BARROS, D. L. P de. Contribuições de Bakhtin às teorias do discurso. In: BRAIT, B. (Org.). Bakhtin, dialogismo e construção do sentido. Campinas: Ed. da UNICAMP, 1997.

BRAIT, B. Bakhtin e a natureza constitutivamente dialógica da linguagem, In: BRAIT, B. (Org.).

Bakhtin, dialogismo e construção do sentido. Campinas: Ed. da UNICAMP,1997.

CONY, A. H. A gestante. Folha de S. Paulo, 05 de junho de 2007, p. 2.

MEAD, G. H. Mind Self and Society from the Standpoint of a Social Behaviorist. Chicago: University of Chicago, 1934.

SOBRAL, A. A Escola Francesa de Análise do Discurso: Elementos para um resgate crítico da noção de lugar social. 1999. 225f. Dissertação (Mestrado em Linguística) - Programa de Pós-graduação em Linguística, Universidade de São Paulo, São Paulo, 1999.

Ato/atividade e evento. In: BRAIT, B. Bakhtin: conceitos-chave. São Paulo: Contexto, 2005. p. 11-36.

Elementos sobre a formação de gêneros discursivos: a fase "parasitária" de uma vertente do gênero de auto-ajuda. 2006. 325f. Tese (Doutorado em Linguística Aplicada e Estudos da linguagem) Programa de Pós-graduação em Linguística Aplicada e Estudos da linguagem, Pontifícia Universidade Católica de São Paulo, São Paulo, 2006.

Do dialogismo ao gênero: as bases do pensamento do Círculo de Bakhtin. Campinas (SP): Mercado de Letras, 2009.

SOBRAL, A.; GIACOMELLI, K. Observações didáticas sobre a análise dialógica do discurso - ADD. Domínios deLingu@gem, v. 10, p. 1076-1094,2016a.

Da relevância do desdobramento das marcas linguísticas em marcas enunciativas na análise dialógica do discurso. Comunicação apresentada no VIII SENALE, Universidade Católica de Pelotas, Pelotas, 2016b.

VOLOSHINOV, V. N. (1930). El signo ideológico y la filosofía del lenguaje. Trad. Rosa María Rússovich. Buenos Aires: Nueva Visión, 1976.

Recebido em: 12/07/17. Aprovado em: 03/04/18.

Title: From meanings to sense: principles for a dialogical analysis

Authors: Adail Sobral; Karina Giacomelli

Abstract: The proposal here presented, which constitutes a part of works in progress, is based on the dialogical theory of language and includes an integrated treatment of the strictest textual-linguistic plan (the so called textual materiality) and of the broader enunciative plan. In this regard, the specific interest of the proposal is to present parameters for a discursive-linguistic work that consider, at the same time, the word in the language system (the level of meaning) and utterances effectively produced (the level of sense) for examining how meanings in the language system are appropriated by discourses and serve to establish senses in enunciations. This conception is based on the idea that words have not a given-for-all sense, but acquire sense precisely in the contexts of use, in which there happen interactions involving specific interlocutors, in activity spheres, and by means of speech genres.

Keywords: Dialogism. Theory and analysis. Analytical parameters. 
Título: De significaciones en la lengua hasta el sentido en el lenguaje: parámetros para un análisis dialógico

Autores: Adail Sobral; Karina Giacomelli

Resumen: La propuesta aquí presentada, que constituye parte de trabajos en curso, se basa en la teoría dialógica del lenguaje e involucra un tratamiento integrado del plan lingüísticotextual más estricto (la llamada materialidad textual), y del plan enunciativo más amplio. En ese sentido, el interés específico de la propuesta es presentar parámetros para un trabajo lingüístico-discursivo que parta, al mismo tiempo, de la palabra en el sistema de lengua (nivel de significación) y de enunciados efectivamente producidos (nivel del sentido) para verificar de que maneras las significaciones en la lengua son apropiadas por los discursos y sirven para instauración de sentidos en el lenguaje. Esta concepción parte de la idea de que las palabras no tienen un sentido dado, pero adquieren sentido en contextos de uso, que involucran la interacción entre interlocutores específicos, en ámbitos de actividad y por medio de géneros.

Palabras-clave: Dialogismo. Teoría y análisis. Parámetros analíticos.

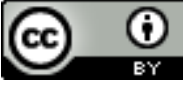

Este texto está licenciado com uma Licença Creative Commons Atribuição 4.0 Internacional. 